\title{
Editorial
}

\section{Christian Hipp}

The first issue of Blätter der Deutschen Gesellschaft für Versicherungs- und Finanzmathematik appeared in April 1950, and the present issue, number onehundred and sixteen, is the final one.

Blätter will be succeeded by the European Actuarial Journal (EAJ).

This new journal is published and edited in cooperation with actuarial associations of the following eleven countries: Austria, Belgium, France, Germany, Greece, Hungary, Italy, Poland, Portugal, Slovenia, and Switzerland.

EAJ is the successor of the following additional five actuarial journals:

1. Belgian Actuarial Bulletin

2. Boletim do Instituto dos Actuários Portugueses

3. Giornale dell'Istituto Italiano degli Attuari

4. Mitteilungen der SAV/Bulletin de l'ASA $(\mathrm{CH})$

5. Mitteilungen der ÖAV (A).

EAJ will start with approximately 6.500 subscribers in Germany and the 10 countries mentioned above.

The aims and scope will be the same as those of Blätter, and the publisher is again Springer, Heidelberg.

The editorial board of EAJ consists of the following distinguished researchers:

Hansjörg Albrecher,

Griselda Deelstra,

Holger Drees,

Alfredo Egidio dos Reis,

Jose Garrido,

Christian Hipp,

Christian Hipp, Karlsruhe, Deutschland, e-mail: christian.hipp@KIT.edu 
Ralf Korn,

Stephane Loisel,

Thomas Mikosch,

Ermanno Pitacco,

Mario V. Wüthrich.

The international readership of EAJ requires papers to be published in English in the print version; papers in other languages may be submitted but they will either be translated to English or published online only.

The journal is designed for the promotion and development of actuarial science and actuarial finance. Using a double blind reviewing process, EAJ will publish original scientific papers, survey papers, as well as papers for the transfer of scientific results to practical solutions. The first issue of volume 1 of EAJ is scheduled for April 2011. Scientists and practitioners are invited to submit their papers to this new journal online via the link http://www.editorialmanager.com/EuAJ. 